\title{
O Chamado Direito Natural: Em Que Consiste.
}

\author{
Witson Chagas
}

(Da Faculdade de Direito de Pelotas da Universidade do Rio G. do Sul)

\begin{abstract}
"Desde que o homem reflete sôbre suas relaçôes, desde que há "sociedade" como tal se fêz problema para êle - escreve KELSEN, no seu estudo sôbre o Direito natural, - não deixou de preocupá-lo a questão de um "ordenamento justo" das relações humanas. $E$ apesar de tôda a História, tôda a história de sofrimentos da humanidade - continua êle pode ser interpretada como um intento único, e sempre renovado sob os mais horriveis $e$ sangrentos sacrificios, de encontrar resposta para essa questão, tal resposta continua a faltar-nos, hoje, como nos faltava no instante em que pela primeira vez relampagueou na alma do homem êste terrivel segrêdo da Justica"
\end{abstract}

\section{Quadro histórico.}

Um dos fenômenos hodiernos no campo da Filosofia jurídica é a ressurreição do Direito natural. Em que consiste o Direito natural? A idéia de um Direito naturaỉ, superior ao direito vigente em cada país e em cada época, é bem antiga. Encontrâmo-la entre os Gregos, sobretudo em Aristóteles que define o chamado "justo por natureza", ou idealmente justo, independentemente das normas escritas, e que estaria esculpido no coração ou na consciência dos homens. Seria êsse o Direito natural, quer dizer, ema- 
nado da natureza mesma das coisas, e da "natureza humana". Em Roma, Ulpiaxo põe igualmente os animais sob a proteção do chamado Direito natural ${ }^{1}$. E êsse conceito de um Direito formado de normas e princípios imutáveis, inscritos na natureza das coisas, e superior a qualquer legislação positiva, se desenvolve e prospera sob a égide dos filósofos estóicos, incorporando inclusive o Direito das gentes (ius gentium) e o direito civil (ius civile). Finalmente, na Idade Média, essa teoria recebe, sobretudo com Tomas de Aquino, um desenvolvimento consentâneo com a civilizacão teocêntrica então dominante, em que à Igreja, como instituição divina, cabia papel relevante na construção da Cidade dos Homens. O caráter imutável das leis naturais se reforça, ao ponto de transmudar-se, de acôrdo com os dados da teologia cristã, em direito sobrenatural e divino.

A partir do século 17 , porém, insurgem-se os filósofos contra essa orientação predominantemente teológica impressa pelos Padres e doutôres da Igreja ao Direito natural. Com Hugo Grócio, o Direito natural passa a repousar na natureza "racional" do homem. Entroniza-se, em lugar de Deus, a deusa Razão. Reivindica-se a liberdade e a igualdade do homem ${ }^{2}$, em face do despotismo do poder teocrático. Voltam-se, os espíritos de vanguarda, contra as leis e as instituições consideradas intocáveis pelas doutrinas jurídicas dominantes, com a sanção do chamado Direito natural. É contra a Igreja e contra o Estado - mórmente contra o Estado absoluto do antigo regime, - que se luta. Surge, então, a Escola Clássica do Direito natural, que floresce nos séculos 17 e 18, no amplo movimento de idéias que acompanha a ascenção da Burguesia e prepara o adven-

1. O Direito natural é aquêle que a natureza ensina a todos os sêres vivos (animalia). Digesto, I. 1.3. Ver nota 7, infra.

2. "Onde quer que tenham sido proclamados como princípioz eternos de justiça a liberdade, a igualdade e a fraternidade dos sêres humanos, os homens seguiram os rastros dos filósofos estóicos" Edgar Bodenheimer, Teoria del Derecho. Fondo de Cultura Economica, México, 1946, p. 113. 
to da Revolução Francesa ${ }^{3}$. Já no século 19 floresce o historicismo: o Direito natural é combatido. Mostra-se o que há de abstrato e metafísico nêle. E vem o positivismo, que leva tudo de roldão, na segunda metade do século. Passa a considerar-se o direito positivo, as normas vigentes, codificadas ou não, em cada país, como o único Direito realmente válido, existente. E a hora da revanche. Destrona-se o "natural" do Direito, ou o puramente racional. Reivindica-se, cada vez mais, a "realidade social" do Direito 4.

Bem diferente è o quadro histórico em que se dá, atualmente, a ressurreição do Direito natural. Agora, é sob o influxo da chamada "ascensão das massas" e do avanço do socialismo, que se elaboram as novas doutrinas do Direito natural. Já não é mais "revolucionário" - como o foi a Escola Clássica do Direito natural ${ }^{5}$, - mas conserva-

3. RECASÉns Siches define a Revolução Francesa “como a apoteose máxima e frenética do Direito natural". Vida Humana, Sociedad y Derecho, 3. ${ }^{\mathrm{a}}$ ed., Editorial Porrua, S.A., México, 1952, p. 388.

4. E um Direito ideal que as escolas do Direito natural perseguem - um Direito ideal, apartado e superior ao da prática jurídica (direito positivo). Este ideal superior do Direito _ um Direito tal como devera ser - não estava em condições de encontrar e reconhecer - Direito real, que regula efetivamente as relações sociais e interhumanas. É só com a constituição da Ciência do Direito, no início do século 19 - com a Escola Histórica, na Alemanha, e a Escola da Exegese, em França - que se dá atenção ao Direito tal como é, ao Direito como instituição social. Só então se constitui, pròpriamente, uma ciência jurídica, voltada para o Direito positivo, ou seja, o Direito dado num tempo e num lugar determinados. “A pretensão do Direito Natural de ser tido como fonte do Direito positivo, foi cancelado a partir de SAvigny. SAcco, com lacônico vigor, constata o fato com a seguinte frase: "Antes de SAVIGNY se entendia que o Direito Natural era uma fonte subsidiária do Direito. Hoje não se costuma reconhecer ao seu reconhecimento sequer o valor de um meio hermenêutico". CARLos Cossio, Teoría de la Verdad Jurídica, Editorial Losada, S.A., Buenos Aires, 1954.

5. Assim como a burguesia foi uma classe revolucionária, da mesma forma foi revolucionária e vanguardeira a Escola Clåssica do Direito natural. 
dor reacionário. Não visa o progresso, e sim a manutenção do statu $q u o^{6}$.

\section{Ordem natural e ordem jurídica. O caráter ideológico do Direito natural.}

Duas idéias são associadas, na elaboração do Direito natural: a idéia de "razão" e a de "natureza". Notaram os Romanos que havia entre os homens, e mesmo entre os animais, "laços de aproximação, solidariedade e até sentimentos que independiam de leis para existir" "Eram essas manifestações gerais e fundamentais da vida gregária, comuns aos animais e aos homens, - escreve Hermes Lima - que o direito natural, na mais clássica de suas definições entre os romanos, abrangia" 7 .

6. “A maior parte das novas filosofias jurídicas que surgiram na Europa em começos do século 20 constituem intentos de fazer face ao socialismo". EDGAR BODENHEIMER, Teoria del Derecho, p. 163 . O Direito natural, diz muito bem ORLANDO GOMEs, "presta-se a objetivos colidentes. É o seu drama". E acrescenta: "Crer na existência de uma lei superior, que deve informar o Direito positivo, é uma convicção cômoda aos descontentes, porque podem confeitar as suas reivindicações revolucionárias com apêlos patéticos à justiça. Mas, a idéia do Direito natural é lâmina de gilete; corta dos dois lados, porque também serve aos contentes. Nenhuma razão é melhor para justificar a preservação da ordem estabelecida do que mostrar que está conforme à natureza das cousas. A insistência com que certos círculos hoje a propagam explica-se pelo interêsse de dar apoio racional a alguns valores cambaleantes". E conclui: "o drama dessa idéia é que, ontem, servia ao progresso, e, hoje, serve à reação" ORLANDo GoMes, Marx e Kelsen, Livr. Progresso Editôra, Salvador, Bahia, 1959, pp. 63 e 66 .

7 Hermes Lima, Introdução à Ciência do Direito, Livr. Freitas Bastos S.A., Rio de Janeiro e São Paulo, $13 .^{\text {a }}$ edição, 1964, p. 245. Os dois sentidos em que é tomado o ius naturale, entre os Romanos: 1) “compreende de ordinário todos os princípios naturais do Direito, evidentes por si mesmos, com as conseqüências nos mesmos contidas. Tais conclusões, enquanto se observam de fato em todos os povos, seja devido ao costume, seja à lei escrita, se chamam ius gentium. O ius gentium é, por conseguinte, quanto ao seu conteúdo, uma parte dêsse 
Foi, como se vê, o que há de "universal", de abrangente de todos os homens, independentemente de lugar e de tempo, o que se quis pensar como Direito natural. É o que há de "permanente" ou "estável" no homem que se quis reconhecer, como direito natural, como estatuto comum dos homens. Seria aquêle conjunto de principios ou normas impostas pela "natureza" do homem e pela "natureza das coisas". Mas todo o problema está em saber em que consiste essa "natureza humana", que é dada como imutável, e em que consiste a "natureza das coisas", ou seja, a Realidade. Ora, êsse problema foi sempre escamoteado, na medida em que o deram por sabido. E mais: na medida em que o deram por resolvido de uma vez por tôdas.

$O$ que se quis, com o chamado Direito natural, foi decretar o caráter absoluto e imutável de certos princípios, dados como "divinos", ou deduzidos da "natureza humana". O que se quis, com êsse rótulo, foi decretar a inviolabilidade da ordem humana, fundada em tais principios. Essa ordem seria uma ordem natural, fundada na "natureza das coisas" Ora, o problema - não resolvido pela teoria ido Direito natural - é que essa ordem não era "natural", mas ao contrário, "jurídica" 8 . Era obra dos homens, e não

ius naturale" 2) "às vêzes é tomado o ius naturale num sentido restrito e diferente do ius gentium. Assim começa o segundo título das Institutas com a doutrina de Ulpiano: "Direito natural é aquêle que a Natureza ensina a todos os sêres, e não é, portanto, peculiar sòmente à espécie humana, senão que pertence a todos os animais, como por exemplo: a união dos dois sexos, a procriação e educação dos descendentes" Victor CATHRein, S. J., Filosofia del Derecho. El Derecho Natural el Positivo, 6. ${ }^{\text {a }}$ ed., Instituto Editorial Reus, Madrid, 1950, p. 176. E CATHREIN conclui: "o D̈ireito natural é considerado como um Direito comum aos homens e aos animais, porque também êstes obram de conformidade com êle".

8. A teoria do Direito natural, diz KeLsEN, "tem às vêzes a tendência de borrar a diferença que existe entre um sistema éticojurídico, isto é, normativo, e um sistema de leis da natureza", "mostrando-se inclinada a interpretar a lei jurídica como uma espécie de lei da Natureza". Hans KeLSEN, La Idéa del Derecho Natural y Otros Ensayos, Editorial Losada, S.A., Buenos Aires, 1946. 
dos deuses. Noutras palavras: trata-se de uma ordem posta (e imposta) por homens, e por isso não poderia ser imutável.

Èsse Direito natural, que encontraria nos estóicos seus principais codificadores, na Antigüidade clássica, assentava na natureza racional do homem, e na natureza maior, que a todos abrange, os fundamentos do Direito. Há, diz Cícero, "uma verdadeira lei chamada reta razão, que é conforme à natureza, aplica-se a todos os homens, é imutável e eterna" 9 .

O ponto de partida dessa ética, e da concepção do mundo em que ela se apoia, é que tudo está dado, de uma vez por tôdas, e como "natureza", no homem e no universo. As leis dessa natureza (humana e universal), são alcançadas pela reta razão (recta rotio), e ao homem cumpre curvar-se diante delas - bem como diante da ordem social e humana da sua cidade, do seu Estado, que só podem ser expressão da "lei natural", da "natureza das coisas" Ressalta o caráter ideológico (de justificação do stato quo) de tal concepção ${ }^{10}$. Pois sôbre ela repousa o chamado Direito natural, ainda hoje invocado pelos doutos, como o supra-sumo da sabedoria humana em matéria de organização social e política. Deixa estar o mundo: o que importa é a infinita superioridade (= suficiência) do espírito ou da razão hu-

9. Cícero, De Officiis. Cfme. Hermes Lima, Introdução à Ciência do Direito, $13 .^{a}$ ed., cit., p. 246.

10. Refere-se KELSEN, excelentemente, no seu estudo sôbre "A idéia do Direito natural", à "afirmação indemonstrada, e indemonstrável para os submetidos à norma, de que a autoridade que estabelece - Direito positivo se encontra de posse do Direito natural, da justiça" E acrescenta: "Pode mostrar-se fàcilmente que se trata apenas do intento de legitimar como Direito natural o Direito positivo, justificar qualquer conteúdo dêste com uma autorização concedida pelo Direito. natural à autoridade que estabelece a norma, e de estabilizar assim uma forma de govêrno autocrático-aristocrática; pois não é Direito natural e sim Direito positivo, porque o que se trata de fundar com isso é uma forma de govêrno". KELSEN, ob. cit., p. 52. 
mana. Eis o pressuposto dessa orgulhosa concepção do homem - concepção que estava destinada a fazer "mundo" na história do pensamento ocidental.

\section{Teoria da justiça ou teoria do Direito em si.}

O que è criado - pela vontade do homem - se tem como "artificioso", ou "não-natural". de certo modo "profano", nas origens dessa Teoria do Direito natural. O Direito natural seria expresssão de uma "ordem justa" na medida em que essa ordem é "dada", é "natural", e portanto permanente. $O$ Direito positivo se apresenta, assim, como uma simples obra humana. "Enquanto procede da insuficiente vontade humana - escreve Kelsen - se apresenta sempre, com relação ao "natural", como mais ou menos "arbitrário" ". E nessa mesma medida não seria "justo" "12.

Portanto, a justiça corresponde a uma ordem natural. Natureza e Justiça se identificam. A ordem natural - ou a ordem universal da Natureza, - é uma ordem essencialmente "justa"; o mesmo vale dizer: tudo o que existe é bom, é justo, é verdadeiro em si mesmo. Ou seja, independente do homem. Não depende do homen para ser "aperfeiçoada" Essa ordem "em si" é precisamente a "ordem natural", que corresponde à Justiça.

Já se vê que, numa tal concepção, o que é "natural" - e por isso necessàriamente justo - é imutável e eterno. Dado uma vez por tôdas. É obra de Deus, ou dos

11. Ob. cit., p. 19.

12. Sôbre a "falsa oposição entre Direito natural e Direito positivo": "A justiça, como valor, integra o dado jurídico, sem que se possa desgalhá-la dêle com o nome de Direito natural (em oposição ao Direito positivo) para nos encontrarmos, depois, diante do problema de compor os membros prèviamente despedaçados do dado único". ENRIQUE R. AFTaLión (e outros), Introducción al Derecho, Tomo II, Librería “El Ateneo" Editorial, Buenos Aires, 5." ed., 1956, p. 357. 
deuses. Os homens estão automàticamente excluídos dessa ordem natural ${ }^{13}$.

Fonte do Direito natural seria a Natureza (vista como Deus, ou como Razão). Já o Direito positivo, promulgado pelos homens, é um Direito "menor", relativo, "falivel", e de alguma maneira "injusto" (ou mais ou menos justo) ${ }^{14}$. Quer dizer que o progresso jurídico, a realização da justiça, não seria obra humana - ao contrário, os homens só poderiam desviar-se da justiça, do direito "justo", na construção da Cidade Terrena. Sòmente a norma de "Direito natural", que é intrìnsecamente justa, tem validade objetiva. o Direito positivo seria apenas formalmente válido, porque promulgado pela autoridade competente ${ }^{15}$.

O Direito natural se apresenta como algo "dado" (metafisicamente). O Direito positivo, como algo "pôsto" (positivamente). Nisto se distinguem estas duas ordens

13. Entre os Gregos, como se sabe, dominava a idéia de que os deuses regem o destino dos homens. Consideravam êles o Direito "como um dom da divindade, como lei eterna, divina..." Catrrein, ob. cit., p. 164. Assim, não se via no Direito o resultado de uma "conquista" do homem e dos povos, mas como um "dom" dos deuses. Era o Direito "revelado" - como revelada era a verdade religiosa. Hesíodo, nos seus Trabalhos e os Dias, observa que "sòmente aos homens Saturno concedeu leis, pois os peixes, o animal na selva e os pássaros do céu vivem da rapina mútua porque carecem do Direito; mas aos homens o Direito outorga o dom soberano". Id., ibid.

14. A "positividade" de um direito - escreve Krisen - consiste "em ter sido legislado pela vontade humana", que é uma razão de validade alheia, por sua essência, à validade própria do Direito natural, já que êste, como ordenação natural, não foi produzido pelos homens, nem pode ser considerado de modo algum como suscetível de ser produzido por um ato humano". HANS KELSEN, La Idea del Derecho Natural y Otros Ensayos, p. 20.

15. As normas do Direito natural - ao contrário do Direito positivo - não são jamais "postas", editadas pelos homens. Trata-se de uma ordem natural, de algo dado uma vez por tôdas, independentemente da vontade humana. Ver ob. cit. KFLSEN, p. 19 ss. 
normativas. Uma, o chamado Direito natural, fala "interiormente" ao homem; o outro, o Direito positivo, se impõe, "exteriormente", ao homem ${ }^{16}$.

O Direito natural é, essencialmente, a tecria do Direito "em si", que se identifica, afinal, com a Justiça. É, neste sentido, uma Teoria da Justiça. Mas o que é, "em si", a Justiça (o Direito natural)? Passará, acaso, de uma "idéia"? E o Direito como idéia pura, que dispensa a sua realização positiva - que está, por isso, divorciado do vir-a-ser da realidade, em que se cometem injustiças, e se luta pelo Direito - não é Direito, por mais "natural" que se pretenda, mas uma simples "aspiração" abstrata de justiça. Essa aspiração é legítima quando faz corpo com a realidade, abdica das excelsitudes de que geralmente aparece nimbada, e vem se bater pelas causas concretas dos homens.

Pressupõe, pois, o Direito natural que haja uma ordem de conexões "necessárias" a presidir os acontecimentos humanos. Essa ordem natural sancionada pela vontade divina, pode justificar a injustiça, em nome de princípios absoiutos e imutáveis. Pode justificar tudo. Daí o que há de perigoso no chamado Direito natural — cujo conteúdo passa a ser a manutenção da ordem existente, a justificação do statu quo.

16. Direito natural nada mais é do que ética, ou moral. Com êsse nome não se designa, afinal, senão o "fôro íntimo", onde fala a "voz da consciência". É o coração do homem, em última palavra e o imperativo moral, o poder de decidir que tem o homem, em face das circunstâncias de sua vida - é êste o conteúdo efetivo do chamado Direito natural. Como afirma LuIZ Legaz Y LACAMbRA, "embora se possa dizer que há um Direito natural válido, êste constitui mais ética do que Direito" (LuIz LEGAZ Y LACAMBRA, Introducción a la Ciencia del Derecho, Barcelona, 1943, pp. 254-274. Cfme. Josef L. Kunz, La Filosofía del Derecho Latinoamericana en el siglo $X X$, Editorial Losada, S.A., Buenos Aires, 1951, p. 60). Neste sentido não se pode negar a existência do Direito natural. 
4. A doutrina estóica da igualdade dos homens. Natureza humana e Direito natural.

Os estóicos, por assim dizer, terminavam no principio, onde seria necessário começar. Um Direito natural comum, baseado na razão, nos identificava, em ZENÃo e seus discípulos, com a razão divina - mas ignorava a nossa condição de homens, ou seja, sêres diferenciados, que não se ajustavam à unidade e universalidade da ordem natural ou divina. O que era a conquistar, se apresentava como dado: a liberdade e a igualdade de todos os homens. O homem estóico contentou-se com um "em si" abstrato e ideal, desinteressando-se pela humanização do homem, o que equivale a dizer: pela realização do próprio Direito. A humanidade era, para os estóicos, um minus, um estado inferior, degenerado - ao passo que o Direito natural era o Direito absoluto correspondente à "idade de ouro" da humanidade. O homem, portanto, era considerado um ser que já fóra perfeito, e deixara de o ser: decaira de sua dignidade própria ${ }^{17}$.

O princípio (estóico) da "igualdade" é, em si mesmo, neutro: dizer que todos os homens são iguais, por natureza, é apontar para o ponto de partida, apenas, da humanização do homem. Desiguais pelas condições sociais e pessoais de cada um, iguais são os homens por natureza: eis o que essa doutrina da igualdade dos homens pretende enunciar. Igual segundo a natureza quer dizer: igual pelo nascimento, pela origem comum da humanidade. Mas é pelo crescimento que os homens se diversificam - e se humanizam. A origem é comum; o desenvolvimento é singular, ou "pes-

17 "O Direito natural absoluto da idade de ouro teve de ser substituído por um Direito natural relativo, não tão perfeito, que, segundo os estóicos, devia levar em conta as condições reais da situação existente e a natureza imperfeita do homem EDGAR BODENHEIMER, Teoria del Derecho, p. 112. 
soal". O que é "comum", no homem, o iguala aos outros homens. É, sem dúvida, esta, a sua natureza (no sentido de que os homens nascem iguais uns aos outros). Mas é o que os diferencia entre si - e no entanto os irmana ainda mais - - o que conta ${ }^{18}$.

Já mostramos que a chamada "lei natural" ${ }^{19}$ pode ser fonte de justiça, tanto quanto, de injustiça. Dependendo do que se pretende tirar dela - e também do que se pretende atingir com ela. É sempre a "comum humanidade" do homem que conta. Mas se considerarmos essa comum humanidade como "natureza" dada uma vez por tôdas, a conclusão a tirar é de que essa humanidade do homem não é a realizar. Conclusão das mais graves, porque implica em "rebaixar" o homem, impedindo-o de crescer, ou de atingir a sua própria "altura".

A "natureza humana" è entendida como "razão", pelos estóicos. Cultivar a razão é cultivar o que há de mais próprio, ou humano, nessa "natureza", e vice-versa. Natureza e razão se identificam, pois, para os estóicos - no homem. "Natureza humana" passa a significar natureza "racional" do homem. O homem é ratio, tanto quanto "natureza". Donde a conclusão de que o não-racional no homem está fora da sua natureza, é inumano. E o que é, no homem, o não-racional? É, pròpriamente, — diremos nós - todo o homem, ou melhor, a totalidade do homem, exceto a razão.

18. A lei moral natural que, segundo Santo Agostinho, Deus escreveu no coração do homem, "era por êle considerada como o trasunto ou a cópia da lei eterna divina, da razão divina soberana e imutável, no coração dos homens". CAthrein, Filosofia del Derecho, p. 179. Mas se silencia, nessa concepção, que tudo depende da evolução ou do desenvolvimento do próprio homem.

19. A lei moral natural seria uma lei inscrita no coração dos homens, uma lei que "nasce" com o homem. "A lei moral natural, diz SANmo Ambrósio, não se escreve, mas nasce conosco, e portanto não é pelo estudo que chegamos ao seu conhecimento, senão que êsto procede do interior da própria natureza e se torna público a todos". Cathrein, Filosofia del Derecho, p. 179. 
Tinha-se como "natural" uma ordem jurídica perfeita, imutável e eterna. Por que "natural"? Natural seria o que é imutável e eterno: o que não varia, e portanto não está sujeito ao tempo, e ao arbítrio humano (como as leis, o direito positivo). Natureza è, pois, um conceito metafísico: há uma "ordem natural", que é verdadeira na medida em que é imutável e eterna. Há, assim, uma "minimização" do humano - oposto ao que é natural.

O Direito, para ser "real", verdadeiro, pretende-se que tenha de corresponder à ordem "imutável" da natureza ${ }^{20}$. A natureza se opõe à história, e por isso seria uma ordem imutável e eterna. A verdade seria o que não muda - $\mathrm{e}$ julgava-se que a natureza era imutável. Daí pensar-se que o Direito fazia parte dessa ordem natural imutável.

Como vemos, essa concepção estática do Direito, chamada Direito natural, casa muito bem com a concepção, também estática, de uma "natureza humana" imutável e eterna ${ }^{21}$. São conceitos que se correspondem e completam, o de natureza humana e Direito natural. Em ambos os casos se quer "imobilizar" o homem e o Direito, negar o seu "devenir".

\section{Quem estatui em definitivo, sôbre o Direito natural?}

Os ideais humanos se incorporam, sempre, na legislação, se convertem em direito positivo. "A maior parte dos princípios que integram o Direito natural - escreve Ricardo Zorraquín Becú - se incorpora à ordem jurídica

20. O Direito, na sua natureza intrínseca, não “fluiria”, não variaria - como acontece com as normas do Direito positivo; seria um Direito imutável e eterno, e por isso verdadeiro fundamento do Direito positivo.

21. A "natureza humana" é uma entidade metafísica. E a Escola Clássica do Direito Natural pretendeu deduzir, racionalmente, os princípios do D. N. de uma natureza humana imutável. Da mesma forma que a escola teológica fundava o Direito Natural na inteligência ou vontade divinas. 
positiva ao ser incluída nas legislações. E isto por exigência includivel da natureza do homem e da sociedade, que não poderiam viver sob um regime distinto" 22 . Por onde se vê que o chamado Direito natural é, mais pròpriamente, uma expressão perifrástica do próprio Direito conquistado pelo homem e pelos povos, no curso da evolução histórica ${ }^{23}$. Dizer, como o faz Santo Tomas, que a lei positiva que contém alguma prescrição contrária ao direito natural não é moralmente obrigatória, porque "já não será lei, e sim corrupção da lei" 24 é esquecer que a lei como algo "pôsto" pela autoridade social, pode existir, sem obrigar os súditos. Ou seja, sem impedir a "resistência" contra ela - a qual pode assumir as mais diversas formas. Mas o problema está em saber quem irá decidir que as normas positivas "violam" o chamado Direito natural. Ou seja: quem estatui, em definitivo, sôbre o Direito natural?

22. Ricardo Zorraquín Becú (e Carlos Mouchet), Introdziccion al Derecho, 4. ${ }^{\mathrm{a}}$ ed., Ed. Perrot, Buenos Aires, 1959, pp. 35/36. E continua êsse autor: "Entre o direito natural e o positivo existe, com efeito, uma relação de hierarquia análoga à que existe entre a Constituição e as leis. Estas últimas devem conformar-se às normas superiores da Constituição, e é isso o que ocorre na imensa generalidade dos casos. Excepcionalmente, no entanto, se sancionam algumas que são logo declaradas contrárias à lei suprema. Foram aplicadas e produziram efeitos antes dessa declaração de inconstitucionalidade, mas não há dúvida alguma de que sua inconstitucionalidade era intrínseca e originária, o que lhes tirava natureza jurídica. Do mesmo modo - prossegue - o direito positivo se ajusta em grande parte ao Direito natural, mas as normas contrárias a êste último padecem de um vício que as priva de todo caráter jurídico. A única diferença que existe entre esta e aquela relação reside no fato de que não há poder algum - salvo o das consciências e o da razão - que declare a anti-juridicidade das leis injustas". Ob. cit., pp. $36 / 37$.

23. Continua Ricardo ZorRaquín Becú, loc. ob. cit.: "Resulta inconcebível, com efeito, a existência de uma comunidade em que se autorizasse o roubo ou o assassinato, se proibisse o cumprimento das obrigações, ou se privasse os cidadãos de certas liberdades elementares".

24. Santo Tomas, Summa Teológica, I-II, 9.95, art. 2 e II-II, 9. 


\section{A luta contra a injustiça: Antígona.}

Existe uma ordem intrinsecamente justa, que valha por si mesma e seja "posta" de uma vez por tôdas, quer dizer, para valer para todo o sempre? - É êste o problema - e a exigência maior - do chamado Direito natural. Com êle se afirma um dualismo invencivel entre ordem juridica positiva e ordem jurídica natural, aquela, contendo preceitos de vigência temporal e transitória, esta, preceitos intemporais e imutáveis. Dualismo que parece irredutivel na concepção jurídica do Ocidente.

O Direito natural não è "editado", não é "pôsto" pelo legislador. Mas seria algo que se impõe (que se "põe") por si mesmo, a todo indivíduo racional, a todo homem. Seria, nesse sentido, um imperativo da razão, o seu reconhecimento. Mais: os preceitos do direito positivo sòmente têm validade plena (e não apenas formal), na medida em que sejam expressão de preceitos do Direito natural.

Como vemos, o problema é complexo ${ }^{25}$. Em que consiste (ou qual o "conteúdo") dessas normas não-escritas e imutáveis do chamado Direito natural? ${ }^{26}$.

25. "A enorme variedade de concepções do direito natural que registra a história - escreve GARCIA MAYNEZ - explica-se em função do grande número de sentidos em que os teóricos empregam a voz natureza. O único ponto em que coincidem os partidários da tese é o da afirmação do dualismo normativo. Mas suas opiniões se separam quando se intenta definir aquela palavra. O fundamento do direito é a natureza; mas, como entender êsse vocábulo? Trata-se da natureza num sentido físico Da natureza racional do homem?.. Ou a validez da ordem natural depende da índole peculiar de seu conteúdo?..." EduARDo GARCLA MAYNES, Introduccion al Estudio del Derecho, Editorial Porrua, S.A., México, 7. ${ }^{\text {a }}$ ed., 1956, pp. 40/1.

26. "A teoria clássica do Direito Natural sempre admitiu escreve WERNER GOLDSCHMIDT - implìcitamente que êste compreendia um conjunto de critérios de valoração, e nunca pretendeu introduzir de contrabando em lugar dêles normas de reparte dotadas como tais de eficácia operativa. Esta substituição se deve mais pròpriamente à ciência jusnaturalista protestante". WeRNER GOLDSCHMIDT, La Doc- 
A ilustração clássica da tese jusnaturalista, na sua expressão teológica, é encarnada por AnTíGona, na peça famosa de Sófocles. Antígona, contrariando o édito real, que proibia dar sepultura a seu irmão Polınıce, e mantém com o tirano Creon o seguinte diálogo:

Creon: - Tu, que inclinas a cabeça ao solo, confessas ou negas ter dado sepultura a PoLINice?

Anrígona: - Confesso, não nego ter-lhe dado sepultura.

Creon: - Conhecias o édito que proibia fazer isso?

Antígona: - Sim, conhecia. Todos conhecem.

Creon: - E ousastes violar as leis?

Antígona: - É que Zeus não fêz essas leis, nem a Justiça que tem seu trono em meio aos deuses imortais. Eu não acreditava que os teus éditos valessem mais do que as leis não escritas e imutáveis dos deuses, posto que és apenas um simples mortal. Imutáveis são, não de hoje nem de ontem; e eternamente poderosas; e ninguém sabe quando nasceram. Não quero, por mêdo às ordens de um único homem, merecer o castigo divino. Já sabia que um dia havia de morrer - como ignorá-lo? - ainda sem tua vontade. E se morro prematuramente, oh! será para mim uma grande sorte. Etc..

Ai, como vemos, as "leis não-escritas e imutáveis dos deuses", se têem como superiores às leis escritas. Mas aí se afirma, também, o valor e a dignidade da revolta humana contra as leis injustas. $\dot{E}$ isto o que importa ressaltar. Luta-se contra a injustiça - é isto o que há de "vàlidamente" imutável e eterno no chamado Direito natural, ou seja, o que há de "válido" e legítimo para o homem nessa ordem superior ao direito positivo, proclamada e defendida pelos partidários do Direito natural.

trina del Mundo Jurídico (Programa de la ciencia jurídica como ciencia socio-dike-normológica), no Anuário III (Tomo I) do "Instituto de Filosofía del Derecho y Sociología" da Universidad Nacional de La Plata, La Plata, 1962, p. 69.

\section{UMVERSDADE DE STO PABUO}

